Valler, D, Phelps, N and Radford, J

Soft space, Hard bargaining: Planning for high-tech growth in 'Science Vale UK'

Valler, D, Phelps, N and Radford, J (2014) Soft space, Hard bargaining: Planning for high-tech growth in 'Science Vale UK'. Environment and Planning C: Government and Policy, 32 (5). pp. 824-842.

doi: $10.1068 / c 1268 r$

This version is available: https://radar.brookes.ac.uk/radar/items/a00e5f62-f69a-4982-920d-d0bdcb015f0b/1/

Available on RADAR: February 2017

Copyright (C) and Moral Rights are retained by the author(s) and/ or other copyright owners. A copy can be downloaded for personal non-commercial research or study, without prior permission or charge. This item cannot be reproduced or quoted extensively from without first obtaining permission in writing from the copyright holder(s). The content must not be changed in any way or sold commercially in any format or medium without the formal permission of the copyright holders.

This document is the postprint version of the journal article. Some differences between the published version and this version may remain and you are advised to consult the published version if you wish to cite from it. 
Soft Space, Hard Bargaining: Planning for High-Tech Growth in 'Science Vale UK'

\author{
David Valler \\ Department of Planning \\ Oxford Brookes University \\ Headington \\ Oxford OX3 0BP \\ UK
}

\author{
Nicholas A Phelps \\ Bartlett School of Planning \\ University College London \\ 22 Gordon Street, \\ London WC1H 0QB \\ UK \\ \& \\ Jayme Radford \\ Department of Planning \\ Oxford Brookes University \\ Headington \\ Oxford OX3 0BP \\ UK
}

Corresponding Author: n.a.phelps@ucl.ac.uk 


\begin{abstract}
The South East of England is Britain's 'problem region' of unsettled administrative and political arrangements centred on a dense web of generally small settlements and their complex interrelations. Surrounding and tied to the international finance and political centres of London, much of the rest of the semi-rural south-east region nevertheless exhibits a degree of polycentricity. Notably, within the South East of England are a series of scientific and hi-tech hot-spots critical to future UK economic growth. However, the achievement of significant growth in and around hi-tech spaces is challenging, given the context of semi-rurality and historic infrastructure shortfalls in some of these locations. Growth is therefore associated with significant planning dilemmas, a situation which has prompted the introduction of 'soft' planning spaces as a means to transcend sclerotic governance structures and planning policy stasis. However, these sub-regional arrangements may also represent a vehicle for the re-assertion of territory, refracting and reinforcing local political conflict rather than cultivating an unambiguous form of post-politics. We illustrate these issues with regard to the emergence of the 'Science Vale UK' area in southern Oxfordshire, and consider some of the broader implications of planning for growth in such a distinctive settlement pattern.
\end{abstract}




\section{Soft Space, Hard Bargaining: Planning for High-Tech Growth in 'Science Vale UK'}

\section{Introduction}

The South East of England is a complex and problematic concept in the UK (Peck and Tickell, 1992). It at once serves as a vast extended suburban hinterland for London, the increasingly dominant core of the UK economy as a whole, and is itself partly independent (Cochrane, 2012) as a constellation of high technology industries (Hall et al, 1986). It is the growth region upon which Thatcherite and New Labour economic development strategies were spatially focused (primarily, but not exclusively, on the financial and producer services sectors) but also has become something of a barrier to national growth, where largely conservative politics within local government have ensured that housing and employment land-releases have not matched demand. Pro-growth strategies among urban, suburban or rural local governments across the region have historically been few and far between. As the structural shortage of housing in the UK and the South East reached an intense pitch so the previous 'New Labour' administrations of Tony Blair (1997-2007) and Gordon Brown (2007-2010) sought through various means regional planning guidance, regional spatial strategies, local-area and multi-area agreements - to cajole growth-oriented strategies in sub-regions that straddle existing local government boundaries. Thus a number of what Allmendinger and Haughton (2010) have referred to as 'soft' planning spaces emerged as focal points condensing such pressures. They include three major growth areas that were licensed by significant central government support and funding under the 'Sustainable Communities: Building for the Future' plan: Milton Keynes, Ashford and Thames Gateway (DCLG, 2003). They also include areas such as South Hampshire (Phelps, 2012) and Gatwick-Crawley that received small scale funding as growth points or were identified as 'Diamonds for Growth' by the now defunct South East of England Regional Development Agency (SEEDA). South Hampshire and Gatwick-Crawley have featured in national and 
regional planning exercises since the 1960s, however, which gives some indication of the extended time frame over which aspirations to unlock potential growth areas have foundered.

In this paper we explore the emergence of 'Science Vale UK' (SVUK), a newly imagined economic and planning space constituted around three major high-tech employment sites in the southern part of Oxfordshire (see Figure 1). This space has been introduced to give some coherence to the three sites and associated spaces of housing growth, and in many ways parallels the broader evolution of soft spaces towards the latter part of the New Labour era. However, as we will see, SVUK is characteristic of the essentially unplanned historical evolution of some major high-tech employment sites in the UK and the South East of England in particular, and their consequent lack of proper economic and physical integration with surrounding settlements. It is apparent also that the constitution of SVUK reflected more instrumental local political concerns, a fact which impacts both on the nature of the area as a soft space and its potential capacity to respond to the structural features which condition its growth.

We begin in the next section of the paper by arguing that the SVUK case is best represented as an 'assemblage' form (Allen and Cochrane, 2007; Anderson and McFarlane, 2011), comprising diverse and separated sites and cross-boundary political compromises and working arrangements in a provisional organizational structure, characteristics which tend to exemplify and extend the planning challenges associated with high-tech growth in the semi-rural South-East of England. We go on to briefly describe the methods used to collect empirical evidence on the SVUK case. We go on in subsequent sections to recount the story of its emergence as a soft planning space contrasting these with some of the hard bargains to be struck over the likes of transport infrastructure. We conclude with thoughts on what the SVUK case reveals regarding a theoretical and practical understanding of planning for economic growth in the greater South East of England. 


\section{Soft spaces and territorial assemblages}

Soft planning spaces were introduced as planning scales proliferated under New Labour, ostensibly to facilitate cross-boundary working and responsiveness to functional economic areas, but also evidently to disrupt existing and potentially sclerotic local government working arrangements and to usher-in significant policy change. In this sense they might be seen as part and parcel of a shift towards 'post-politics' (Allmendinger and Haughton, 2011; Swyngedouw, 2007), essentially 'defining-in' growth as an inherent aspect of the new spaces concerned and thereby pre-empting alternative responses. The soft spaces which emerged might be regarded as a product of 'territorial assemblages' of governance (Allen and Cochrane, 2007). This stresses the manner in which networks of relations among government and non-governmental bodies and actors have congealed as assemblages in order to mobilize imaginaries for and act upon such spaces, where the soft planning spaces concerned rarely coincide with territorial jurisdictions of government authority and political power. Allen and Cochrane direct much of their analysis toward questioning the notion of regions within the UK, in line with the regional and subregional arrangements introduced by the New Labour governments at that time. Here, they suggested,

'the governance of regions, and its spatiality, now works through a looser, more negotiable, set of political arrangements that take their shape from the networks of relations that stretch across and beyond given regional boundaries. The agencies, the partnerships, the political intermediaries, and the associations and connections that bring them together, increasingly form "regional" spatial assemblages that are not exclusively regional, but bring together elements of central, regional and local institutions' (Allen and Cochrane, 2007: 1163).

Subsequently, it might be noted, there has been some thinning-out of the congested terrain of planning, as the Conservative-Liberal Democrat Coalition Government under David Cameron removed the regional tier of planning, along with centrally-sponsored mechanisms for cross- 
boundary working such as Multi-Area Agreements. However, there is ongoing churn here, with the introduction of Local Enterprise Partnerships in 2011 and latterly City-Deals, and it is clear that in some cases the momentum behind particular soft spaces has been retained, such that they remain an important aspect of the planning policy arena.

It might be suggested that the conceptual foundations for soft spaces are more fully elaborated theoretically than the processes through which such territorial assemblages are constructed. Soft spaces are representative of the broad shift towards networked forms of decision-making, reflecting the increasing importance of cross-boundary and multi-scalar working in a vastly more fluid and interconnected governance environment. The notion of assemblages emphasizes how the geographical fixity implied in vertically-organised means of government (such as coercion and command) has been eroded by flows of finance, information, political, human and symbolic capital (Allen and Cochrane, 2007). These vertical means have been joined increasingly by 'horizontal' means (such as reciprocity, modelling and seduction) of governing such flows. In particular, the latter imply a degree of policy and practice mobility within governance arrangements. ${ }^{1}$ Yet, integral to the notions of soft space and territorial assemblage is also recognition of the stickiness of formal territorial arrangements and institutionalised policy frameworks, and authors are careful to acknowledge the enduring claims of established government jurisdictions. Allmendinger and Haughton describe (2010: 813), for example:

... for all its attention to themes such as flows and nodes, spatial planning has to work within the realities and complexities of bounded space. Indeed, it is clear that there are multiple spaces and scales that planners must negotiate, some of which are more fixed and formal than others. Moreover, whilst policy spaces and scales may be socially constructed, not all are equally fluid or privileged and, when planners begin to organise through

\footnotetext{
${ }^{1}$ See Phelps and Wood (2011) for more detail on these points.
} 
particular spaces rather than others, some will gain more purchase than others, influencing, for instance, where new infrastructure is provided.

The outcomes of these competing impulses are, of course, complex and spatially differentiated. It is perhaps not surprising, therefore, that theoretical interpretations of the emergence of soft spaces are somewhat limited, given the diversity of such spaces, their fuzziness, and their disparate origins and motivations. Allmendinger and Haughton identify three characteristic forms of soft planning space which goes some way towards locating the various motivations and institutional forms involved, as follows: (i) 'bottom-up functional', where local actors come together to engage with major cross-boundary growth opportunities or development locations; (ii) 'shadow' plans and strategies on different scales which effectively short-circuit slow-moving statutory planning processes in favour of a focus on delivery; and (iii) 'top-down functional spaces' driven by central government departments and focused explicitly on economic development and competitiveness (op cit, 2010: 811-812).

Clearly, detailed empirical research is necessary to further inform our understanding of the nature and development of soft spaces, and their impacts on policy outcomes. There is a need for detailed investigation of, for example: the composition of soft spaces, their emergence into policy arenas and associated statutory plans and policy guidance; the respective roles of public, private and other actors in the inception and management of such spaces; the organisational and other interactions which exist between soft spaces and the hard structures of local government; and the extent to which policy outcomes on the ground are influenced by the presence of soft space forms.

We take forward some of these themes in our analysis of SVUK, stressing three qualifications when applying the notions of soft planning spaces and assemblages to this case. First the 
territoriality of local government are absolutely central to the politics and planning for housing and employment growth in the South East of England. Indeed territorial boundaries are often the focal point for quite minor but bitter battles regarding the siting of additional land for housing and associated infrastructure. Moreover, some old planning instruments - such as green belts have themselves hardened into important and enduring territorially-defined foci for local politics in their own right. Second, the science parks and high-technology employment sites in SVUK have existed as camps largely detached from the surrounding residential or employment environment and indeed local government political and planning context, being either currently or previously run by arms of central government or now as self-contained and fully owned corporate territorial enclaves. Third, then, to the extent that territorial assemblages have emerged to mobilize a soft planning space like SVUK they have to deal with both the vicissitudes of representative territorial politics and the administration and planning of these camps that exist somewhat outside of the local planning and political framework.

\section{Research Methods}

The paper draws upon a body of detailed primary and secondary research conducted during 2010-2012. Empirical information was gathered in part from observation and recording of well over 100 speeches and contributions in key South Oxfordshire District Council (SODC) meetings, notably those concerned with the Council's emerging 'core strategy', the central part of the district's Local Development Framework under the 2004 Planning and Compulsory Purchase Act. This was undertaken both in November 2010, at the 'proposed submission stage' of the core strategy prior to its submission to central government, and again in November 2011 at the subsequent SODC core strategy 'Examination in Public'. Additionally 30 interviews were undertaken with key informants including members and officers of SODC, neighbouring Vale of the White Horse District Council (VOWH) and Oxfordshire County Council, property owners and developers including MEPC Plc (owners of Milton Park) and Goodman Plc (Developers at 
Harwell Oxford), the Home Builders Federation, representatives of housing developers including Taylor Wimpey and Berkeley Homes, the 'Didcot Ring of Parishes', Didcot Town Council, SVUK and other interests. The research has also been triangulated with further extensive secondary material including numerous submissions and reports as part of SODC's core strategy process, and local media coverage.

For the current paper we draw on a subset of this material to analyse the problems of unblocking growth when big science exists in a semi-rural framework. We present the story of SVUK as a case study (Yin, 1989) where it is difficult to disentangle the phenomenon under study from its wider context. This is doubly pertinent in our case since the phenomenon of science parks that essentially compose the economic interest to the SVUK case appear as discrete camp-like sites that yet can hardly be separated from their natural and man-made settings. In this respect, although SVUK could be considered rather unique as a case study area of high-tech employment, we consider it as a case study with insights valuable by extension (Burawoy, 1991) to the rest of the South East region in which much of the UK's high-tech activity exists in a similar context. While we should be careful about treating this example as typical of the UK experience, it is certainly instructive in terms of setting the relationship between UK science and technology parks and contemporary patterns and processes of urbanization and associated planning dilemmas in sharp relief.

\section{Science Vale UK}

SVUK came into use in 2008 to delimit a space which encompassed the towns of Didcot, Wantage and Grove, and the predominately hi-tech employment centres of Harwell Oxford, Milton Park and Culham Science Centre. The area accounts for about $4 \%$ of total R\&D employment in England and 13\% in the South East area (OxonCC, 2010). It could be considered a 'bottom up functional' soft space in Allmendinger and Haughton's (2010) terms, but one that 
remains crucially detached from its national, region and even county-wide context - one that has been mobilised by familiar territorial political agendas and yet is attempting to act upon quite impermeable or bounded 'science park' entities.

Figure 1: SVUK area (highlighted) and wider context

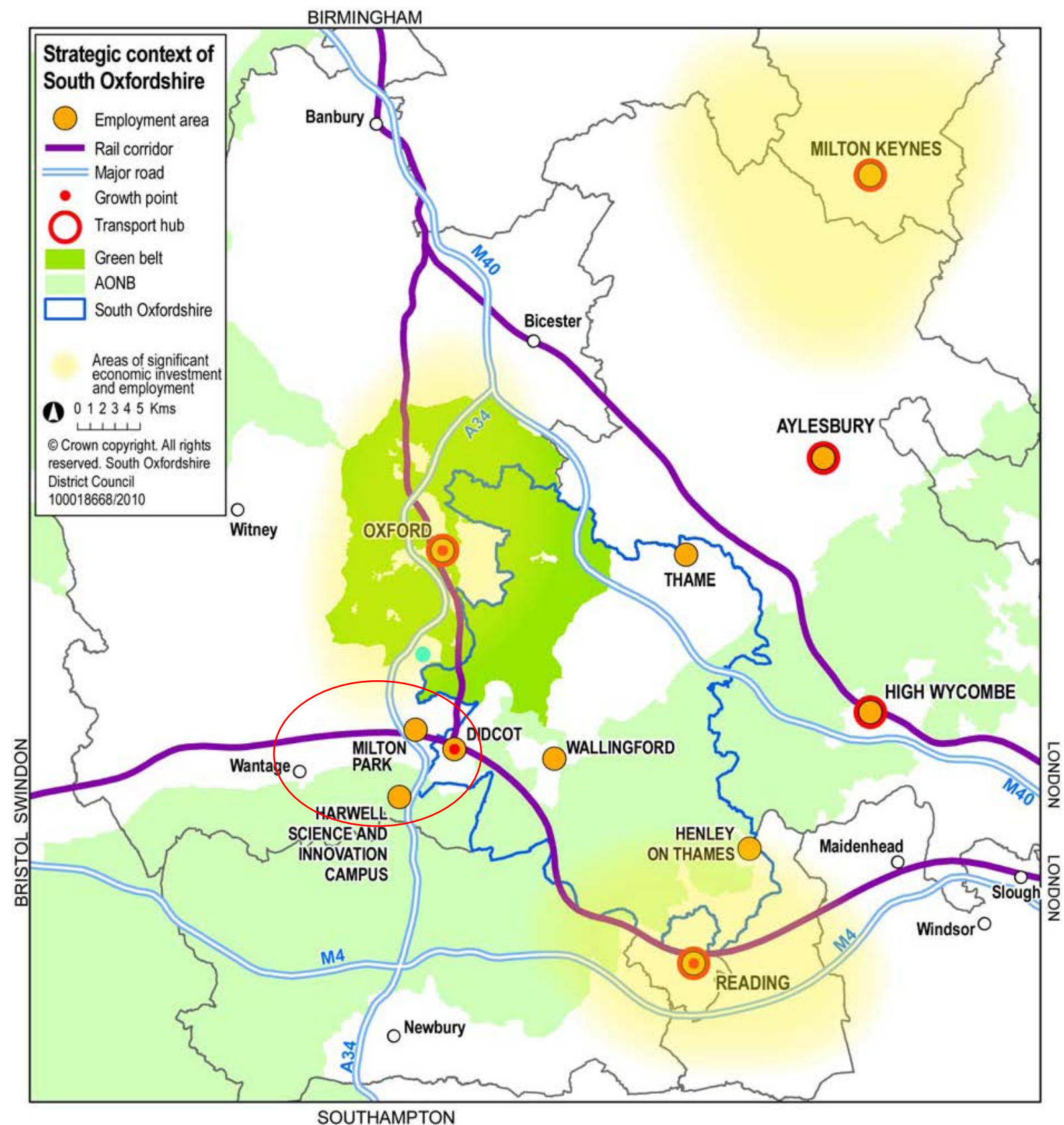

Source: Adapted from South Oxfordshire District Council Core Strategy, Proposed Submission Version, December 2010 


\section{Three hi-tech sites in a soft planning space}

Milton Park is central to the SVUK area and strategically placed next to the A34 trunk road which connects the port of Southampton on the south coast and the manufacturing centres of the West Midlands. In the post-war years it had been a Ministry of Defence supplies depot located for its excellent railway access, but it was the first of the three SVUK sites to be privatized and operated by a commercial real estate company and is home to a diversity of industries. The depot site was auctioned for sale in 1971 and commercial floor space tripled under several owners before the purchase of the site by current owners MEPC in 1984. Remnants of its military past in the form of 'temporary' depot structures - often highly sought after by small high technology companies - remain visible. Even as a commercial operation it nevertheless remains somewhat detached from the planning system since the freehold to the entire site including the roads and adjacent pieces of land are owned by property and development company MEPC, with the only obvious restriction on development being pressure from local communities attempting to preserve a presumption in favour of building heights not exceeding two storeys. Milton Park is now one of Europe's largest multi-use business parks, hosting more than 160 companies employing around 6,500 people, with particular strengths in the bio-tech and ICT sectors (Lawton-Smith, 2010; Boon, 1997; Boon and Gashe, 2001).

\section{Figure 2: Aerial view of Milton Park}

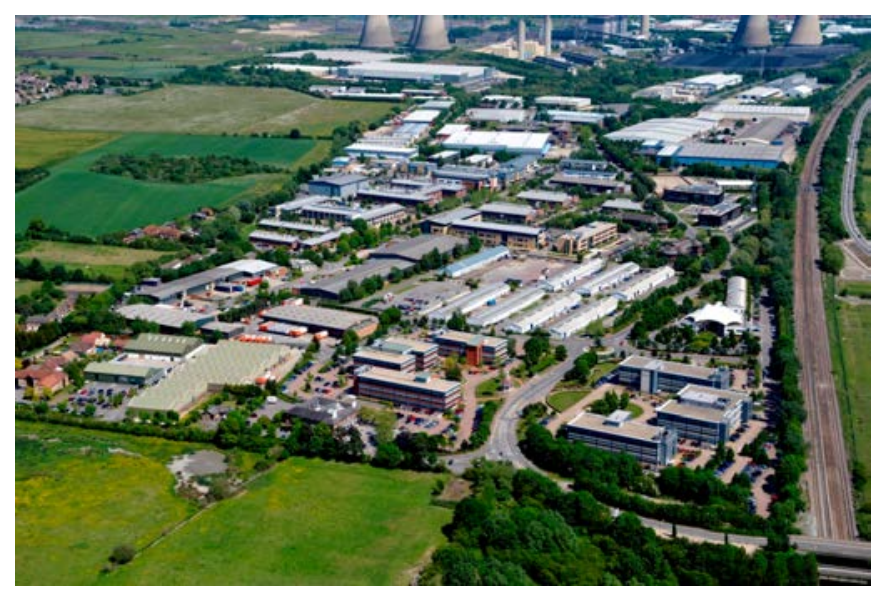

Source: $M E P C$ 
The success of Milton Park has, in important respects, resulted from an accidental planning policy context. The 100 hectare site was initially highlighted for small scale light industrial development in Oxfordshire County Council's first Structure Plan (1979), under B2 (general industrial) and B8 (storage and distribution) land use classifications. Branded as 'Milton Trading Park,' the site accounted for a large percentage of Oxfordshire's industrial, warehouse and distribution activity. A number of factors contributed to the change in approach for planning at Milton Park. Firstly, in 1980 Oxfordshire County Council was subject to the removal of development control powers, in favour of the Vale of White Horse (VOWH) District Council, which was able to employ a broader range of land use classification in the area. In addition, changes in planning policy allowed greater flexibility for VOWHDC. This included the '1987 Use Classes Order' and the '1988 General Development Order' issued by central government for planning guidance purposes. The changes in planning legislation introduced 'Class B1' as a land use classification (Boon \& Gashe, 2001), meaning that a large amount of land and the very substantial existing floorspace allocated for warehousing and ancillary activities could be redeployed for other commercial activities without requiring planning permission for a formal change of use. Consequently, planning policy for office, high-tech and light-industrial activities became considerably more flexible and accommodating. This facilitated a much wider range of development at Milton Park compared to the previous Structure Plan commitments, resulting in an increase in office-based employment and a purposeful re-positioning as a base for high-tech activities.

It is worth noting, however, that regardless of the removal of development control powers in the late 1980s, Oxfordshire County Council expressed serious reservations regarding the growth of the site. The County Council emphasised the loss of existing land-uses and that such significant growth in employment may also attract an unmanageable level of demographic and residential growth (Oxfordshire County Council, 1987). Overall, then, as the research of Boon and Gashe 
(2001) illustrates, Milton Park is a site that emerged quite accidentally as the by-product of more wide-ranging changes in the planning system, in many senses developing in spite of statutory development planning policies.

In comparison, the development of Harwell Oxford has been led predominately by public sector growth and investment. Royal Air Force base Harwell was established in the 1930s and was used throughout World War II until late-1945. In 1946 the Atomic Energy Research Establishment (AERE) was created by the Ministry of Supply at the Harwell site, with a focus on research and development for nuclear power. During a ten year period of rapid development and construction, the 'UK Atomic Energy Authority' (UKAEA) formed at Harwell with the Rutherford Appleton Laboratory soon after. The UKAEA was given a 'Special Development Order' (SDO) by the Government in 1954, which allowed building of any kind in the pursuit of nuclear energy. However, as nuclear research activity on the site was gradually wound-up the SDO was removed in 1997, meaning that development on the site would be subject to the normal operations of the UK planning system. Significant areas of land are currently restricted for future development as a result of the decommissioning of the nuclear facilities and related land. However, the vast 385 hectare site now functions on a commercial basis with the majority of UKAEA privatised as AEA Technology Plc (UKAEA, 2010) and the site managed as a locked 50/50 joint venture between AEA/Science and Technology Facilities Council and business/science park property company Goodmans. Harwell is a leading site for bioscience research in the UK, with both the Diamond Synchrotron, the UK's largest investment in science for 30 years and ISIS, the world's largest pulsed neutron source onsite, together with the Science and Technology Facilities Council, the Rutherford Appleton Laboratory, the Medical Research Council and European Space Agency Space Centre amongst others, with more than 4,500 people working in over 140 organisations. 
Figure 3: Aerial view of Harwell

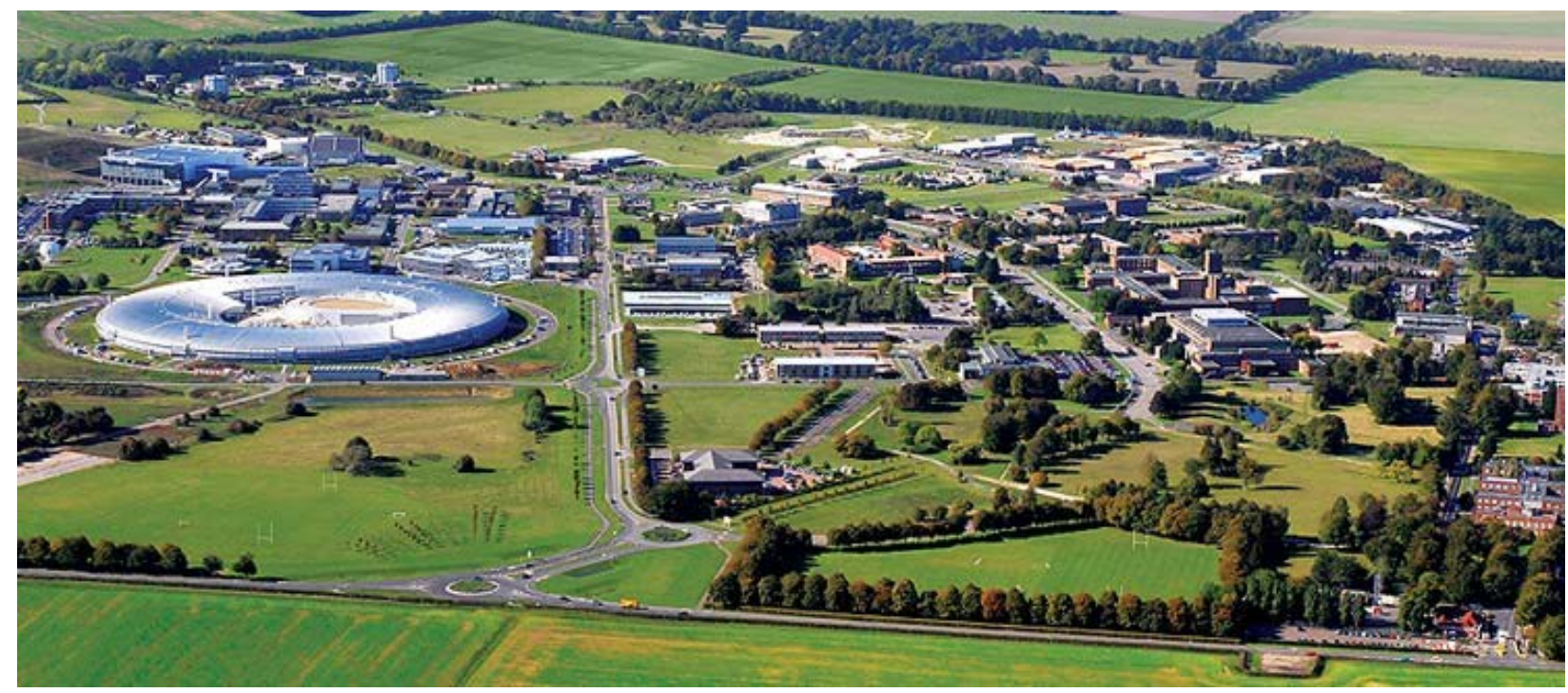

\section{Source: UKAEA}

Culham Science Centre is the third major employment site in SVUK. Located in the greenbelt of South Oxfordshire, the 80 hectare site is the location for the UKAEA headquarters and currently the world's largest Fusion Experiment; the 'Joint European Torus' (JET) conducted within the Culham Centre for Fusion Energy research centre. In parallel with Harwell, Culham had been a military outpost during the Second World War, housing the Fleet Air Arm's Royal Naval Air Station, HMS Hornbill. The airfield was closed by the Admiralty in 1956 and transferred to the UKAEA as an offshoot of Harwell in 1960. It now hosts an 800,000 square metre scientific research site that includes two major nuclear fusion experiments, as well as a variety of related and spin-off enterprises.

As this initial outline suggests, SVUK is made up of diffuse and disparate entities. The three major employment sites are quite distinct in terms of their character and their future development requirements and are physically separated from each other across 10 miles of relatively open countryside. They are also woven around an intricate network of historic villages and near to formally designated Green Belt and Areas of Outstanding Natural Beauty. Two of the three sites 
are poorly connected to, if not somewhat isolated from, significant settlements and population, reflecting their histories as sensitive wartime military establishments and subsequently government nuclear research institutes. While SVUK has emerging advantages in terms of its location in relation to national road, rail and air networks, and given the significant road improvements that have been undertaken in recent decades to improve access to motorways and major trunk roads, the infrastructure shortfall within and surrounding this soft planning space is clearly evident (Figure 4 gives a flavour of typical road conditions in the area). The area is characterised predominantly by small two-lane roads, a lack of alternative routes between the various sites, bottlenecks produced by two single-lane bridges across the Thames and limited rail and public transport options. Importantly, each site has functioned, and to some extent still continues to function, somewhat outside the formal planning system and to a degree beyond the attentions of local governments and the new networks or assemblages of governance that might seek to mobilise them. Additionally, we might note that the SVUK site as a whole is bisected by the administrative boundary between SODC and VOWHDC, adding a further complication to the planning context. To a large degree, therefore, the respective sites themselves have been essentially unplanned in formal terms and relatively detached from broader strategic planning processes. The sites have not been developed as integrated or self-contained entities and have operated quite separately from other key aspects of development activity; it is noteworthy, for example, that the three major sites contain almost no housing provision. In many respects, therefore, these might be seen as individual and differentiated 'clumps' of high-tech activity (Forsyth, 2011) projected onto a mainly rural background, rather than integrated and planned 'campus-garden' developments (Forsyth and Crewe, 2010). 
Figure 4: Village lanes - A415

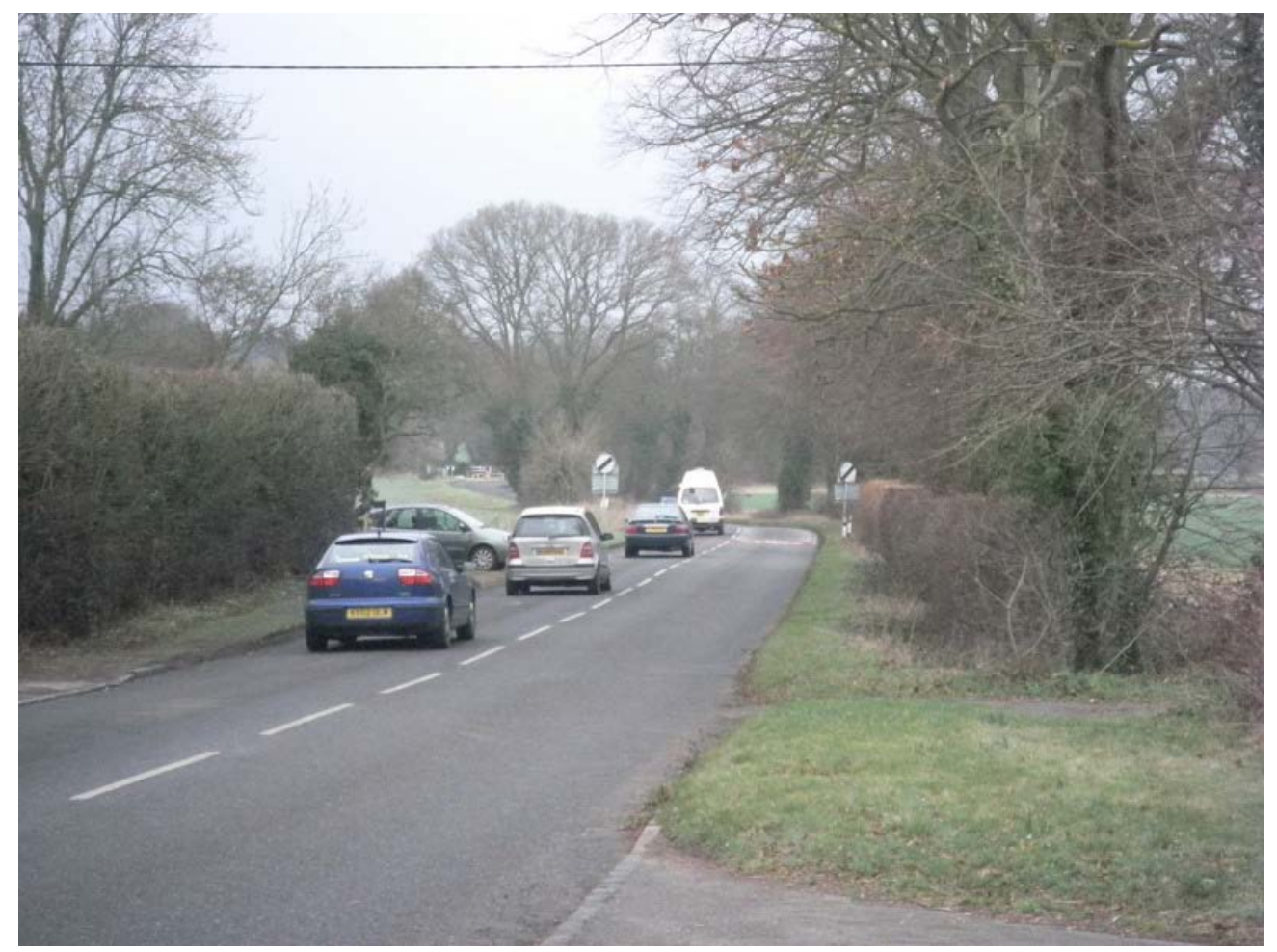

Source: Authors' photograph

In light of this, the process of imagining and governing SVUK as a coherent high-tech space is fraught with difficulties. There are significant challenges of mobilising popular, political and technical support and of coordinating appropriate funding streams across jurisdictions, something we consider further below in relation to transport infrastructure. There is the challenge of constructing and maintaining a meaningful identity for a new soft planning space and a capacity to act upon it, as well as the critical task of integrating future development potential into the wider strategic planning of a semi-rural, village-based environment. Here the mobilization of SVUK, however contingent, is some sort of evidence that "new political realities are assembled around particular concerns without necessarily ever being fully integrated into some overarching unified set of understandings' (Cochrane, 2010: 371-372). There is also, as we have suggested, the problem that such an emergent governance assemblage is attempting to act upon high-tech sites that have historically been partially or wholly removed from wider representative and participatory democratic political processes of local government planning 
activities. Nevertheless, SVUK has emerged as a soft planning space which has been recognised in formal planning policy and official documentation and has gained some traction in securing support for planned growth both across local government boundaries and across the three major commercial sites.

\section{The Emergence of SVUK}

The SVUK concept (known initially as the 'Quadrant') emerged at the tail end of the era of Regional Economic Strategies (RES) established under the New Labour Governments (19972010) and the parallel enabling of cross-boundary agreements across local government districts (so called Multi-Area Agreements) designed to promote new planning spaces at the sub-regional scale. The agenda nationally was upon encouraging strategies for the delivery of employment and housing growth, with a corresponding recognition that many key growth areas and points would straddle existing local government boundaries. There is a clear sense in which the move towards SVUK was facilitated by these broader developments, and it was subsequently officially recognized in the South-East Regional Spatial Strategy (RSS - The 'South East Plan', SEP) in 2009. However, the initial impulse for introducing the forerunner of SVUK also reflects rather more parochial concerns. In 2006-7 the then Chief Executive Officer at VOWH introduced the notion of a 'Quadrant' based around Wantage, Grove, Harwell and Milton Park (and incorporating Didcot) as a mechanism for competing more effectively for funding allocations within Oxfordshire, given a perception that current arrangements were favouring Oxford city and other areas of the county rather than the Vale. A senior executive officer at SODC/VOWH reflected in interview:

It was the then Chief Exec at the Vale was the person who thought - I'll be honest, I believe this was his primary objective - here we were sitting in this area of the Vale with these phenomenal companies and this fantastic potential, but it was such a poor relation to 
Oxford. His district council was not faring well in the way funding was being cut up even within Oxfordshire. It was a Lib-Dem district council, but a Conservative county council, and in some ways if you look at the expenditure profiles they would probably bear that out. So there were always tensions between that individual and the County Council. They didn't fare very well, and so he talked to me about this idea of a 'Quadrant' around Wantage, Grove, Harwell and Milton Park - and it sort of crept onto Didcot. His objective was to say 'look, we're here and we're not being recognised and there should be money and investment coming in'. That's where it really started, with that individual.

As the idea took shape and was taken forward by senior officials, it became apparent that planning officers in the districts were seen as increasingly out of step with the growth agenda that was beginning to emerge. Planning officers - who were by now shared across SODC and VOWH - and planning policy were viewed by Council executives as inflexible and preoccupied by environmental concerns, and as such would have to be reoriented towards planning for growth in the area. The senior officer went on to describe the process through which such redirection was cultivated as SODC moved towards its new core planning strategy, the central part of its Local Development Framework under the 2004 Planning and Compulsory Purchase Act, from 2008:

I set up a team of senior politicians who took the lead on SODC's core strategy and that was partly because at that time our planners' thinking was lagging quite some way behind the political aspirations. Left to those planners... well, they were holding us back. They were all about protecting the environment - a unique environment - but their prioritisation was all about protection and we couldn't shift their thinking. So we had a team of senior politicians who worked on it who were very employment-oriented, very focused on the need to increase wealth, and to make life easier and painless in terms of planning processes for business. Some businesses were experiencing the pain of working with planning. So the 
politicians set the vision and the objectives within the core strategy. (Senior Council Executive, SODC/VOWH, 4 August 2011).

In addition, anticipating potential opposition amongst some local politicians, senior officers worked with the leading group of committed pro-growth Councilors to cement the powerful vision around the emergent SVUK project:

We built up a very strong cohort of politicians centrally around this phenomenal success story. If we hadn't had SVUK as an entity we would not have succeeded here. We said: Look at what we've got here - the bioscience cluster at Milton Park, the cryogenics, the space centre, ISIS, the Diamond Synchrotron, and of course Culham with JET ['Joint European Torus' - European fusion experiment] and MAST ['Mega-Amp Spherical Tokamak' - UK fusion experiment]. Phenomenal international projects. In fact, our politicians had never understood what was on their doorstep. They never understood it. So we organised bus tours - we took them to Diamond and JET etc. and it was: 'Wow'! These were epiphanies for a lot of those individuals, and they bought the vision. (Interview, Senior Officer, SODC/VOWH, 4 August 2011)

Following the initiation of the SVUK concept, moves were undertaken to substantiate the idea in organizational terms and to drive the project forward. SVUK was formalized in organizational terms as a partnership with a management board drawn from the district and county authorities, UKAEA, MEPC, STFC and the South East England Development Agency, though serviced directly on a very limited basis predominantly by a single employee. A consultants report was commissioned in 2007 to investigate the nature and economic potential of the SVUK area, though this served to underline the sense of relative neglect felt in the districts in the of south of the county since it argued that the competitive position of SVUK - its scale and image - when set 
against the universities and their science parks in and around the city of Oxford to the north (SQW, 2007).

Nevertheless, the SVUK concept has become well-established as a planning entity and is referenced widely in formal planning documentation including, for example, the (former) SouthEast Plan (SEP), Oxfordshire County Council transportation policies and the Local Development Frameworks and Core Strategies of relevant district councils. It also underscored a broader shift in Oxfordshire's overall planning context marked initially by the South East of England Development Agency's adoption of the Regional Economic Strategy in 2006 and subsequently incorporated into the SEP. A representative of the County's Spatial Planning and Infrastructure Partnership commented:

Harwell, Culham, Milton Park... they're all key areas of activity. There has been a change of emphasis over time. You can go back a couple of structure plan periods certainly, and economic growth was almost a dirty word in Oxfordshire. Looking at Oxford (city), it was: 'you don't want to overheat the economy'. The underlying theme in a couple of structure plans was: 'well, ok, we want to support the rural economy, we do want to push housing out to the county-towns because we want to protect the greenbelt around Oxford'... but jobs hadn't necessarily flowed. There was an element where the Structure Plans were trying to encourage economic growth outwards, to match the 'housing for sustainable communities' point of view, rather than saying we need to get full square behind the area as a powerhouse engine of the economy. With the Regional Economic Strategy and the introduction of idea of the Central Oxfordshire 'Diamond for Growth', there was a change of focus. That is, we needed to look at things more carefully in terms of what we're trying to do, and the natural assets of Harwell and Culham and Milton Park all coming together started to do that. Then you started to get your key ribbon of development up the A34: 
SVUK in the south, Oxford city, and, in a different way, Bicester to the north of the county (Oxfordshire SPIP officer, Interview 22 March 2012).

By late-2011, however, SVUK no longer employed any individual directly, and its status was under consideration, especially in the light of the newly-arrived Oxfordshire Local Enterprise Partnership, introduced in March 2011. Also, while our interviews revealed quite widely-held support for SVUK as a suitable basis upon which to promote future economic growth and associated development, even amongst groups who have major reservations regarding particular sites, there is also a view that the project runs up against the unavoidable politics of territory and the strictures of formal planning policy. The comments of a developer/consultant in response to the question of whether the existence of SVUK had changed the way planning is approached were instructive:

I think it has. There's a definite feeling that all the different organisations are trying to pull together. For example, infrastructure. We've had discussions with the County Council about the strategic road links - how it's going to be funded and how we put together the Infrastructure Delivery Plan. There's been a more coordinated approach... but then again probably not as coordinated as it could or should have been. We've been pointing out for some time that it's odd that you've got two councils working on SVUK, bringing forward two core strategies. They've actually got the same management team, the same Chief Executive, the same Head of Planning and Head of Planning Policy, and yet they've got two completely separate core strategies that are running to different timescales. They've got an upcoming Didcot Area Action Plan which actually will cross the boundary - but this AAP is not going to deal with the big issues. The big issues are dealt with first, through the separate core strategies. So, yes, SVUK has made a difference on a day-to-day level; it's brought people together, it's 
got people talking about infrastructure delivery, about employment, about where the housing is going. But in terms of the actual planning mechanisms, the actual process of plan-making, it hasn't. It's almost outside of Planning that people are now talking to each other and working, but inside Planning it's still very much the old system which is creaking along. I see it as a two tier approach.

What this suggests is that in spite of the resonance of the SVUK concept and its role in underpinning a shift away from the growth constraints associated with the Structure Plan era, it remains a fragile entity largely inserted into, rather than transforming, the formal mechanisms of planning policy and the existing politics of territory. Indeed, the process of imagining and governing a new soft planning space such as SVUK necessarily and quite quickly resolves itself into a host of practical and technical considerations regarding strategic issues such as allocations of land for housing and finding and funding appropriate transport infrastructure improvements. We go on to consider in more detail the deliberations over how to provide for greater accessibility to the three key sites across the SVUK area.

\section{Hard Bargaining: The Example of Transport Infrastructure}

The distinctive physical form and historical evolution of SVUK has given rise to intractable problems regarding the unblocking of future growth in the area, not least with regard to transportation infrastructure. A number of factors contribute to this: First, southern Oxfordshire is characterised by a dispersed population in villages outside of the main towns of Didcot, Wantage and Grove, a pattern which places significant demands and constraints on the transport infrastructure in the area. Car ownership is particularly high; in 2001, 46.9\% of households were in ownership of two or more cars, compared to the average of the South-East region at $27.9 \%$ (Kier and Goodman 2008). Secondly, the hi-tech sites are located away from the main towns, creating a disaggregated set of elements that will contribute towards planned growth. Thirdly, the 
predominantly rural road network and the main A34 have, at peak times of the day, been operating at capacity for some time already.

Notwithstanding these constraints, the SVUK area is programmed for significant growth with approximately 13,000 net additional dwellings and 12,000 additional jobs planned by 2026 (OxonCC, 2010: 8). The major allocations of housing and projected employment growth have in fact remained unchanged despite the new Conservative-Liberal Democrat Coalition Government's revocation of the SEP, the RSS under which these growth proposals were formalized. Indeed, while many local authorities seized the opportunity to reduce often politically unpopular housing allocations under the RSS system, decisions in southern Oxfordshire to support the growth commitment at SVUK are revealing of some of the commitment to underpinning growth in the area (see Valler, Phelps and Wood, 2012). This is despite the perceived fear that housing development will occur without improvements in the accompanying road and other infrastructure. In terms of road infrastructure particularly these fears are not without some basis and serve to underline the historically disarticulated nature of planning for growth not just in SVUK area but also elsewhere (While et al, 2004; Phelps, 2012).

The prospects for significant transport infrastructure investment are clearly circumscribed by policy set at national scale. Rhetorically, at least, the Coalition Government is committed to infrastructure as a centrepiece of its growth agenda. The approach was emphasised in a series of publications including 'Local Growth: Realising Every Place's Potential' (BIS, 2010) and the 'Plan for Growth' which called for 'fundamental improvements in infrastructure systems' in the UK (HM Treasury/BIS, 2011: 13). The National Infrastructure Plan set out funding allocations and initiatives to enable innovative local infrastructure solutions (HM Treasury, 2011). However, this referred primarily to the Regional Growth Fund (RGF) announced in June 2010. The RGF allocated $£ 1.4 \mathrm{bn}$ for projects to lever-in private sector investment and remove dependency on 
public sector funding. The SVUK Partnership submitted an RGF bid for the area that sought to further facilitate road development planning to underpin exceptional growth potential in southern Oxfordshire. The bid aimed to deliver $£ 60$-70m investment over a 20 -year plan period in order to support the proposed residential and employment development. The partnership emphasised that $60 \%$ of the overall investment required would be contributed via Section 106 agreements, therefore unlocking potential for private sector investment. The bid highlighted that without public sector funding, private firms were unlikely to invest in strategic transport priorities, resulting in 'market failure'. It also argued that after 2017 the growth potential of SVUK would be severely compromised by increasingly problematic infrastructure constraints (SVUK Partnership, 2011). However, the bid was unsuccessful, apparently due to a combination of factors: the long time horizon of job creation connected with road improvements (15 years); that job creation would be indirect (in the form of retaining or attracting companies to SVUK); and a lack of up-front commitment from the private sector to part-fund roads.

More generally, the problems of financing infrastructure directly and indirectly related to development are enormous in the vacuum created by the current context of fiscal austerity coupled with incomplete proposals for new funding mechanisms like the Community Infrastructure Levy (CIL) that have emanated from central government. Funding for strategic infrastructure projects has been reduced considerably leaving increased emphasis on developer contributions associated with new development as the critical basis for infrastructure delivery. The Coalition Government's early withdrawal of significant Department of Transport funding to Oxfordshire County Council for transportation infrastructure effectively removed the $£ 62 \mathrm{~m}$ 'Access to Oxford' programme agreed by the previous Labour Government in 2007, which had incorporated a series of measures for the A34 important to the functioning of SVUK, including junction improvements both within and outside the SVUK area, and active traffic management schemes. 
Prior to the present public expenditure cuts, the arrival of the Regional Economic Strategy and the introduction of the Central Oxfordshire 'Diamond for Growth' in 2006 had prompted Oxfordshire County Council to undertake considerable research and preparatory work to identify strategic transport infrastructure priorities in the southern part of the County. A series of transportation reports ${ }^{2}$ were subsequently integrated into the 'SVUK Transport Study' (OxonCC, 2011b), which itself was embedded within the Local Transport Plan 3 (LTP3) for Oxfordshire (OxonCC, 2011). This set out strategic and transport priorities and proposed infrastructure investments as described in Table 1 and illustrated in Figure 5.

Table 1: Strategically important transport infrastructure proposals

\begin{tabular}{|c|c|c|}
\hline Scheme & Town/Village & Cost \\
\hline \multicolumn{3}{|l|}{ Improving the road network } \\
\hline Harwell Strategic Link Road & Harwell & \multirow{6}{*}{$£ 42.5 \mathrm{~m}$} \\
\hline Harwell Field Link Road & Harwell & \\
\hline Rowstock Western Link Road & Didcot & \\
\hline Wantage Eastern Link Road & Wantage & \\
\hline Junction improvements & All of SVUK & \\
\hline Traffic calming for surrounding villages & All of SVUK & \\
\hline \multicolumn{3}{|l|}{ Other: } \\
\hline Improve bus services & All of SVUK & $£ 11.5 \mathrm{~m}$ \\
\hline Improve cycling and walking network & All of SVUK & $£ 2.0 \mathrm{~m}$ \\
\hline
\end{tabular}

Source: OxonCC, 2011

As Table 1 illustrates, these schemes are expected to cost approximately $£ 56 \mathrm{~m}$ in total. The proposals are sought to mitigate the direct impacts of residential and employment development in SVUK, in addition to the cumulative impact of overall development in the area on the Oxfordshire strategic highways network. The LTP3 'Integrated Funding Block' allocated specific rounds of funding to a number of strategic areas of transport policy throughout the plan period (2011-2030). In the case of SVUK however:

\footnotetext{
${ }^{2}$ Initially, a private transport consultancy was sourced to help establish an evidence base of transport infrastructure required to address issues that may restrict growth in southern Oxfordshire; this became known as the 'Southern Central Oxford Transport Study' (SCOTS). However, after the consideration of the growth potential around the SVUK area, it was decided to integrate the SCOTS analysis with that of the 'Didcot Integrated Transport Study' (OxonCC, 2005) and the 'Wantage \& Grove area Strategic Transport Study' (OxonCC 2005).
} 
'LTP3 only guarantees the County Council $£ 200,000$ per year. This is only $£ 3 m$ over the SVUK plan period in addition to the $£ 8 \mathrm{~m}$ we already hold. With the required road schemes at present estimated at $£ 42.5 \mathrm{~m}$, we currently have a funding shortfall of around $£ 32 \mathrm{~m}$ (County Council Transport Officer, 6 January 2011).

Figure 5: Future Roads and Housing Development at SVUK

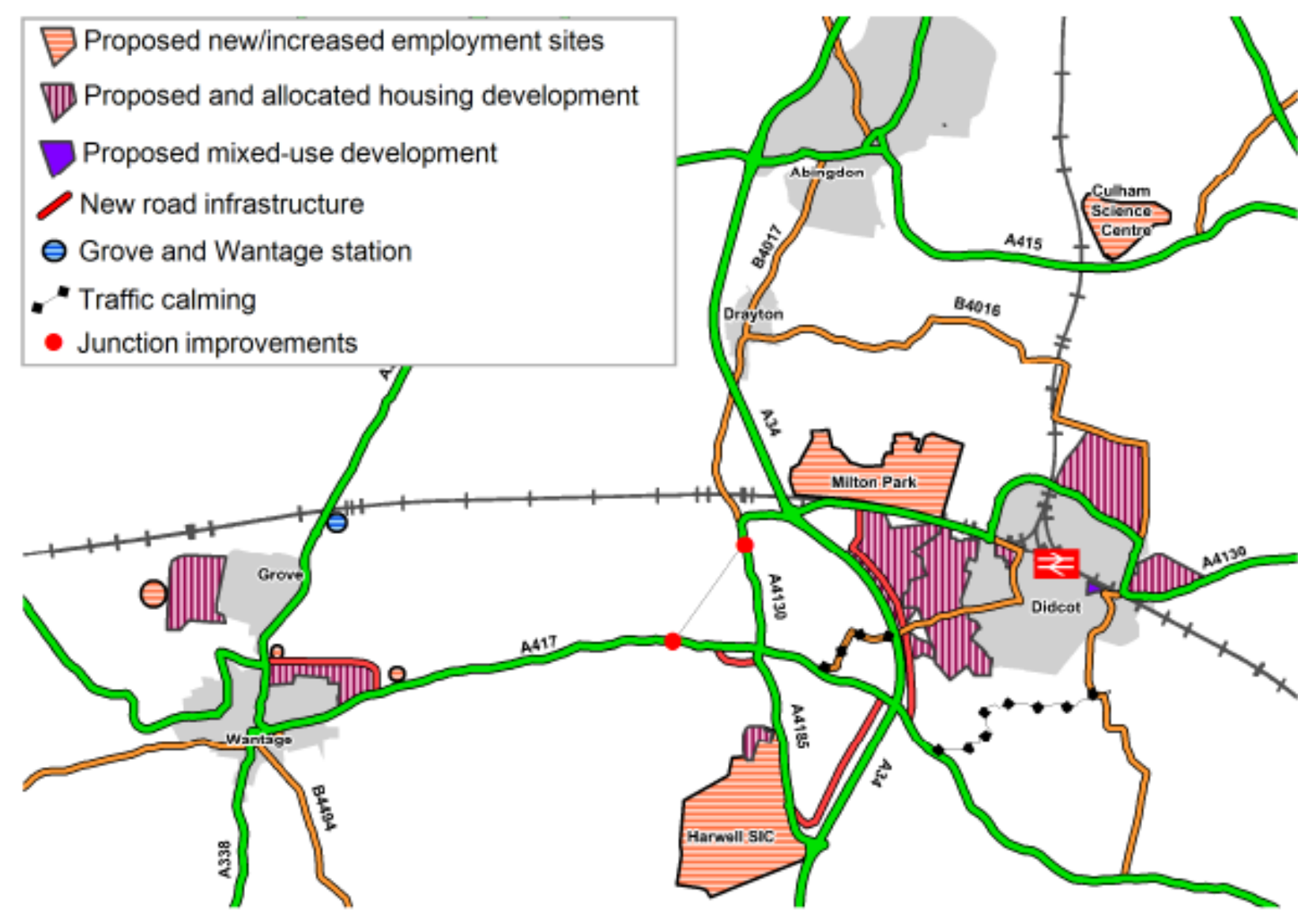

Source: Adapted from Oxfordshire LTP3, OxonCC, 2011

Given the substantial funding shortfall for the delivery of strategically important schemes, and in light of an early lack of progress towards implementing CIL, Oxfordshire County Council's transport planning team commenced in 2011 an assignment to address developer contributions for SVUK. The work sought to propose a methodology for the collection of contributions as a precursor to CIL. A County Council transport planner described: 
'At the moment the fallback position - which is looking fairly promising in terms of deliverability - is that the developers pay for it. Calculations that we have currently done in our loose opinion doesn't make the sites unviable. Obviously the developers may have a different opinion, but it's not that far off what we're currently seeking per dwelling or per job. So we feel that probably in terms of delivering the overall package... once all of the section 106 money has come in then it's fine' (Interview, 6 January 2011).

At present, however, it should be noted that only $6 \%$ of planning permissions in England contribute financially to infrastructure development (CLG, 2008). CIL, in contrast, would ensure that all developments, regardless of size, contribute financially to transport infrastructure in SVUK. There are however, a number of important issues to address before this can be seen as a feasible approach to funding infrastructure not the least of which is how planning for growth negotiates the rather several nature of the high-tech sites involved. Also, financial contributions can only be sought from developments that are new or are increasing gross floor space. For example, an attempt to take contributions per square metre for B1a, B1B and B8 use at Culham Science Park may not be feasible. Specifically, under the CIL regime the County Council would not be able to request any financial contributions from Culham Science Park due to the nature of development at this site. In this case there is no planned change in gross floor space, which would be subject to CIL charges. Rather Culham Science Park is categorised as 'redevelopment' which, under the current regime, is deemed positive for the local and national economy, and therefore should not be presented with additional financial barriers.

Additionally, here, although it appears vital that the County Council seek to provide for the area's collective infrastructure needs, the appetite of the private sector in this respect is likely to be limited. For example, contributions of $£ 4 \mathrm{~m}$ were received only recently from MEPC for 
junction improvements to the A34 at the Milton (Park) Interchange and it is hard to see additional commitments coming forward as an interviewee highlighted:

'I mean MEPC would not do that now. That's major money. Having made that decision and going ahead, and then the recession hitting, you know... they won't do that again! That was exceptional, and don't forget it was absolutely critical. For them, that's their front door. So they had to make really difficult decisions about that. We don't want to get to the financial issues generally with SVUK that we got into with Milton Interchange specifically' (SVUK Representative, 6 July 2011).

A further point arises here relating to the Joint Infrastructure Delivery Plan (IDP; SODC/VOWH, 2011) developed on the basis of the SVUK Transport Study that would provide the evidence base to underpin the district councils' Core Strategy documents and demonstrate how infrastructure will be provided to enable the planned level of growth. The IDP documents for SVUK sought to provide a list of transport schemes associated with the strategic housing and employment sites, classifying them in terms of importance as 'critical', 'necessary' or 'preferred'. The district councils appeared confident that development would not be permitted if 'critical' infrastructure was yet to be delivered. However, it is noteworthy that not one strategic transport scheme was categorised as 'critical' in this document, and while the schemes in question clearly present high priorities we might speculate that there could be legal challenges when residential developers submit planning applications within SVUK, but seek to reduce the potential CIL charges associated with transport infrastructure provision.

Within the overall context of substantial constraint on transport infrastructure provision, the introduction of CIL as a new method of collecting standardized contributions towards infrastructure provision in support of development adds a further dimension to hard bargaining 
over soft planning spaces. At the present time Oxfordshire local authorities are consulting and negotiating over the level of CIL, which will be set by the district councils and Oxford City Council who become the charging and collecting authorities. The respective charging structures will reflect the councils' perceptions of infrastructure needs arising from proposed new development in their areas, as set out in the relevant Local Development Frameworks, along with their judgement of the likely impact on development viability of the proposed charge. As a report from the Oxfordshire Spatial Planning and Infrastructure Partnership makes clear (Oxfordshire SPIP, 2011), the intent of CIL is not that charging rates should be used as a planning or economic development tool with which to compete with other authorities, though the early indications are that this may be evident in some cases. Also, there will be a need for a coordinated approach to the provision of key strategic and cross-boundary infrastructure, and councils will be subject to a general 'duty-to-cooperate', though this 'is not clearly defined and is a matter for local interpretation and negotiation' (Oxfordshire SPIP, 2011). In this context it is perhaps not at all surprising that the County's SPIP highlights the potential for significant difficulties:

Without questioning the Oxfordshire authorities' willingness to co-operate with each other and infrastructure providers it may not be enough to rely upon bilateral negotiations between collecting authorities and infrastructure providers as a means of transferring CIL revenue where this is needed to fund strategic, cross-authority, or indeed cross-county, infrastructure, which serves the wider interests of the Partnership (Oxfordshire SPIP, 2011)

In many respects the prospects for significant improvements to major transport - particularly roads - infrastructure seem remote. It would appear that in the absence of substantial central government investment, and given the potential complexities and tensions of CIL, the likelihood 
is one of relative stasis regarding the central infrastructural challenges in and around SVUK, along the lines of recent experience:

One of the big challenges for Oxfordshire is that with the three growth areas in the county, SVUK, Oxford and Bicester, they are all serviced by the A34. Yet to a point each authority is having their own individual conversation with the Highways Agency. It'll be: 'a little bit of improvement on junction $\mathrm{X}$, or junction $\mathrm{Y}^{\prime}$. But if you keep chucking more and more development on the route up from Southampton to Birmingham, and then really important knowledge-based growth is deterred from any of those nodes along the A34, then there's a problem. I'm not saying it can be made into a motorway - certainly there are sensitive ecological areas where it can’t. But actually, it's ending up with piecemeal changes doing little bits of tweaking and not really solving the problem, rather than saying if we're going to do it, we will just have to make a hard decision and say money is needed to change parts of the A34. In the end, if there has to be a strategic road taking freight up from Southampton up to the Midlands, and at the same time you've also got to facilitate hi-tech knowledge exchange between different companies in the area which do need to engage with each other - then it puts a lot of pressure on a limited road network (Oxfordshire SPIP officer, Interview 22 March 2012).

\section{Conclusion}

As a new planning space, SVUK is an emerging story built around a complex assemblage of governance in Allen and Cochrane's (2007) terms. In fashioning something of a common agenda for SVUK, this assemblage or network of interests has sought to embrace three rather different physical sites and diverse private and public sector interests. To some extent this has reinforced a growth agenda introduced as part of the Regional Economic Strategy in 2006 and extended by the South East Plan in 2009. These regional frameworks certainly shifted the planning context in 
Oxfordshire from a previously defensive and protectionist stance to one more clearly oriented towards growth, and SVUK forms an important part of this agenda. To a degree, then, the emergence of SVUK clearly reflects some of the post-politics inherent in the term 'sustainability' that has pervaded planning practice (Cochrane, 2010) and the many soft spaces (Allmendinger and Haughton, 2010) promoted under the later New Labour years.

Yet growth is in no sense a unified proposition. Built into the very conception of SVUK are existing agendas and prior institutional relationships which militate against any unambiguous form of growth-orientated post-politics. Indeed, SVUK might well be seen as the latest incarnation of a policy conflict in Oxfordshire played out over an extended period in County Council Structure Plans which have directed growth and resources away from the city of Oxford, in favour of the expansion of the smaller county-towns. SODC and VOWH have sought to maintain and further this agenda through the introduction of SVUK and there is little doubt that this conflict will re-emerge in the difficult processes of CIL charging and allocations. In many ways, therefore, SVUK is an expression of pre-existing territorial tensions, and its presence as a soft-space in no way negates ongoing conflict and competition amongst the various local authorities in Oxfordshire. SVUK, instead of opening up an unchallenged 'post-political' space upon which to impose a growth agenda, in practice and in detail produces any number of new lines for political contestation as has the rhetoric of sustainability in planning more generally in the South East of England (Abram, Murdoch and Marsden, 1996; Cochrane, 2010). The lines of political contestation apparent often serve to highlight their lineage in long-entrenched cultures and assumptions that can inhere within planning (notably at the county scale in Britain).

If, as seems plausible, the strength and durability of new sub-regional soft planning spaces will be a reflection of the coherence, including the regional accessibility and internal connectivity, of those spaces then SVUK appears as a problematic space within a problem region. Plainly there 
are considerable challenges in terms of roads infrastructure provision for development at SVUK. In many respects these highlight the dispersed characteristics of the area and the assemblage form of governance which pertain. There are, for example, intractable problems posed by the physical nature and location of the existing developments and the constraints of the established infrastructure, which pose significant challenges to the future growth of the area. Governance of the area is somewhat provisional and the limits of private sector investment in transport infrastructure provision are increasingly recognised. Also, we might suggest that planning for such investment still in many ways reflects the assumptions of the pre-austerity era. Arrangements for potential transport infrastructure funding are at best formative, and these have not been strengthened significantly by the arrival of the Oxfordshire Local Enterprise Partnership (LEP) in March 2011 or the announcement of an Enterprise Zone for SVUK in August 2011. In these circumstances there must be some grounds for scepticism regarding the scope for substantial local infrastructure investment in the context of ongoing national austerity.

Moreover, the distinctive conditions of the South East of England would seem to suggest that this case will be anything but unusual. Certainly, the politics of housing and infrastructure provision will be critically important to the achievement of science-based high-tech growth in many parts of the outer-South East. To date, the development of the arc of high tech employment in the outer South East of England (Hall et al, 1986) has occurred largely in spite of the local government system and its political, planning and economic development agendas. It remains to be seen whether SVUK as an initiative embracing some of the UK's most important 'bigscience' installations can endure as a new planning space offering valuable insights into how intractable questions regarding the unblocking of growth in sustainable and politically acceptable ways might be addressed in the South East of England. This soft planning space, as a new vehicle for the playing-out of a long-standing territorial politics will continue to be symptomatic of what is arguably a peculiarly British scattered and non-contiguous morphology of 
development, including high technology industry. The relationship of science to settlement space in Britain appears to be one not of science in the city, nor, for the most part, of science in the garden suburb campus (Forsyth and Crewe, 2010) but of science in villages and market towns detached from an adequate framework of housing, service and transport infrastructural preconditions necessary for its longer term reproduction.

\section{Acknowledgements}

We are grateful to four anonymous referees and to Andres Rodriguez-Pose for their helpful comments on a previous draft of this paper. 


\section{REFERENCES}

Abram, S., Murdoch, J. and Marsden, T. (1996) "The social construction of "middle England": the politics of participation in forward planning', Journal of Rural Studies 12: 353-364

Allen, J. and Cochrane, A. (2007) 'Beyond the territorial fix: regional assemblages, politics and power', Regional Studies 41: 1161-1175

Allmendinger, P. and Haughton, G. (2010) Spatial planning, devolution and new planning spaces Environment \& Planning A 28: 803-818

Allmendinger, P. and Haughton, G. (2011) Post-political spatial planning in England: a crisis of consensus? Transactions of the Institute of British Geographers NS 37. 89-103

Anderson, B. and McFarlane, C. (2011). Assemblage and geography. Area. 43 (2), pp. 124127.

BIS (2010) 'Local Growth: Realising Every Place's Potential' Department for Business, Innovation and Skills, London. HMSO.

Boon, E.A. (1997) 'The development plan process: out of touch and out of line?' RICS Cutting Edge Report. London. Royal Institute of Chartered Surveyors

Boon, E.A. Gashe, T. (2001) 'Can Economic development be Sustainable?' RICS Cutting Edge Report. London. Royal Institute of Chartered Surveyors

Burawoy, M. (1991) 'The extended case method' pp. 271-280 in Ethnography Unbound: Power and Resistance in the Modern Metropolis. University of Chicago, Berkeley.

Cochrane, A. (2012) 'Making up a region: the rise and fall of the "South East of England" as a political territory', Environment \& Planning C 30: 95-108

Cochrane, A. (2010) 'Exploring the regional politics of "sustainability": making up sustainable communities in the South East of England' Environmental Policy and Governance 20: 370-381

Department for Communities and Local Government (2008) 'Valuing Planning Obligations in England: Update Study for 2005-06’ London. DCLG. Downloaded: 1 July 2011

Available at:

http://www.communities.gov.uk/documents/planningandbuilding/pdf/obligationsupdatestudy.pdf

Department for Communities and Local Government (2003) 'Sustainable Communities: Building for the Future' London. HMSO.

Forsyth, A. (2011) 'Campuses, corridors, and clusters: Alternative forms of the science district' Paper presented at: 'Science and the city: Comparative perspectives on science and technology parks' Science and Technology Policy Institute, Seoul, Korea. 6 Oct. 2011. Copy available from author

Forsyth, A. Crewe, K. (2010) Suburban technopoles as places: The international campusgarden-suburb style Urban Design International 15, 165-182 
Hall, P. et al (1987) Western Sunrise: The Genesis and growth of Britain's major high-tech corridor. Allen and Unwin, London.

HM Treasury (2011) ‘National Infrastructure Plan’ HM Treasury, London. HMSO

HM Treasury/BIS (2011) 'Plan for Growth' HM Treasury/Department for Business, Innovation and Skills, London. HMSO

Kier Property Developments Ltd and Goodman UK Ltd (2008) 'Employment and Residential Development North Oxford Gateway Framework Travel Plan: Client Draft'

Available at: http://www.oxford.gov.uk/Direct/7715347FrameworkTravelPlan.pdf

Downloaded: 15 December 2011

Lawton-Smith, H. Glasson,J. (2010) 'Milton Park: developing a successful high-tech business park' Part 1 in National Endowment for Science, Technology and the Arts (NESTA) report Local knowledge: Case studies of four innovative places London. NESTA. 7-19

Oxfordshire County Council (2011) 'Local Transport Plan 3 (2011-2030)' Available at: http://www.oxfordshire.gov.uk/cms/content/local-transport-plan-2011-2030

Downloaded May $30^{\text {th }} 2011$

Oxfordshire County Council (2011b) ‘Science Vale UK Transport Study’ Available at: http://www.oxfordshire.gov.uk/cms/content/science-vale-uk-area-transport-strategy

Downloaded June 152011

Oxfordshire County Council (2010) 'Access to Oxford’ Oxford. Oxfordshire County Council

Oxfordshire County Council (2007) 'Southern Central Oxford Transport Study (SCOTS)' Oxford. Oxfordshire County Council

Oxfordshire County Council (2005) 'Didcot Area Integrated Transport Strategy' (DidITS) Oxford. Oxfordshire County Council. Hard copy available from: $\underline{\text { 1ts.team@oxfordshire.gov.uk }}$

Oxfordshire County Council (2005) Wantage and Grove Area Strategic Transport Strategy (WAGASTS) Oxford. Oxfordshire County Council. Hard copy available from:

1ts.team@oxfordshire.gov.uk

Oxfordshire Spatial Planning \& Infrastructure Partnership (2010) 'Oxfordshire Local Investment Plan' Oxford. Oxford. Oxfordshire SPIP. Available at:

http://www.oxford.gov.uk/Direct/OxfordshireLocalInvestmentPlan.pdf

Downloaded June 152011

Oxfordshire Spatial Planning \& Infrastructure Partnership (2011) 'Community Infrastructure Levy' Paper 5 to SPIP Partnership Meeting, 22 September 2011. Available at:

http://portal.oxfordshire.gov.uk/content/public/oxfordshirepartnership/Partnerships/spip/220911/i tem6.pdf

Downloaded 25 January 2012

Peck, J. Tickell, A. (1992) Local modes of social regulation? Regulation theory, Thatcherism and regional development Geoforum 23.3. 347-364. 
Phelps, N.A. (2012) An Anatomy of Sprawl: Planning and politics in Britain. Routledge, London.

Phelps, N.A., Wood, A.M. (2011) 'The new post-suburban politics?' Urban Studies 48 (12):

$2591-2610$.

SQW (2007) Evaluation of the economic and employment growth potential of the southern central Oxfordshire quadrant. SQW Consulting, London.

SEERA (2009) 'The South East Plan' South East England Regional Assembly, Guildford

South Oxfordshire District Council/Vale of White Horse District Council (2011) 'Joint Didcot Infrastructure Delivery Plan'. Downloaded August $11^{\text {th }}$ 2011. Available at:

http://www.southoxon.gov.uk/sites/default/files/Didcot\%20IDP\%20Final\%20as\%20at\%20Marc

$\underline{\mathrm{h} \% 202011 . \mathrm{pdf}}$

South Oxfordshire District Council (2010) 'Core Strategy: Proposed Submission Version'. Downloaded 10 February 2011. Available at:

http://www.southoxon.gov.uk/sites/default/files/Web\%20-

\%20Complete $\% 20$ Core $\% 20$ Strategy $\% 20$ Reg\% $\% 2027 \% 20 v 6 . p d f$

Swyngedouw, E. (2007) 'Impossible 'sustainability' and the postpolitical condition', in The

Sustainable Development Paradox D Gibbs, R Krueger (eds) Guilford Press, New York 13-40

Valler, D.C., Phelps, N.A. and Wood, A.M. (2012) 'Planning for growth? The implications of localism for "Science Vale", Oxfordshire, UK', Town Planning Review 83: 457-488

While,A.H., Jonas, A.E.G., Gibbs, D.C. (2004) Unblocking the city? Growth pressures, collective provision, and the search for new spaces of governance in Greater Cambridge, England Environment and Planning A 36, pages 279-304

Yin R. (1989) Case Study Research. Sage, London. 